\title{
FROM THE HISTORY OF THE DEVELOPMENT OF MUSICAL SCIENCE AND THE ACTIVITIES OF REPRESENTATIVES OF MUSICAL SCIENCE IN UZBEKISTAN IN THE FIRST HALF OF THE XX CENTURY
}

Murtazova Sahodat Burievna ${ }^{1}$

${ }^{1}$ Karshi Engineering and Economic Institute, Associate Professor of the Department of History of Uzbekistan, (PhD) Doctor of Philosophy, E-mail: sahodat@ mail.ru

\begin{abstract}
The article summarizes the development of musical science in Uzbekistan in the first half of the twentieth century, as well as the efforts of representatives of the industry. It also highlights the activities of scientists who worked in this area in the 1920s and 1930s, as well as specialists evacuated to Uzbekistan as a result of World War II.
\end{abstract}

Keywords: music, note, ethnography, makam, instrument, institute, expedition, World War II, evacuation, art history, tanovor, textbooks, folklore, composer, research.

\section{Introduction}

In the early years of Soviet rule in Uzbekistan, research in the field of music was characterized by the recording and publication of classical music and Uzbek folk songs. VA Uspensky, EE Romanovskaya, VM Belyaev were the first to study and record Uzbek folk songs and began research in this area.

In 1920, the Ethnographic Commission was established under the Turkestan People's Commissariat of Education under the leadership of VA Uspensky, which was tasked with studying the traditions and peculiarities of the Uzbek people and recording Uzbek songs.

Especially noteworthy during this period were the efforts of musicologists to study the art of classical music. In 1923, VA Uspensky first recorded "Shashmaqom" in Bukhara, performed by masters of art Ota Jalal and Ota Giyas, and published it in 1924 [1, p. 4]. From the masters of the maqom in their time the original features of the maqoms, the recording of samples, became of great importance.

The Khorezm version of Shashmaqom was first recorded and published by musicologist EE Romanovskaya. Matniyoz Yusupov and Ilyas Akbarov were also involved in this work [3, p. 41].

From 1929, the recording of Uzbek folk music was carried out at the Tashkent Music College. The results of research conducted by musicologists have been published in pamphlets and collections. For example, NN Mironov, M. Belyaev prepared works on Uzbek national music and musical instruments. M.Ashrafiy, Sh.Ramazonov, T.Sadikov, researchers of the Samarkand Research Institute of Music and Choreography also took part in this work.

In 1930, the "Scientific Department for the Study of Uzbek Music" was established at the Tashkent Music College. At the initiative of the members of the department in 1931 the first musical folklore expedition to the Fergana Valley was organized. The expedition included V.Uspensky, E.E.Romanovskaya, I.Akbarov, H.Muhamedova, who visited the towns and villages of the Fergana Valley and recorded about 200 folk songs [8].

The most knowledgeable people of his time in the field of music, such as Ota Jalol Nosirov, Abdul Aziz, Abdurahmon Umarov, Domla Halim Ibodov, worked at the Research Institute of Music and Choreography in Samarkand. The staff of the institute has made some progress in researching and developing the Uzbek musical art. The staff of the institute organized music and ethnographic expeditions to collect Uzbek folk songs and prepared textbooks on the theory and history of Uzbek music in the Uzbek language.

In 1934 EE Romanovskaya and I.Akbarovs went to Khorezm [4, p. 17], in 1936 E.Romanovskaya together with the poet Sh.Sadullaev organized an expedition to Bukhara and recorded more than 100 Uzbek and Tajik songs on phonography [9, 4 -v.]. In addition, they recorded many Uzbek songs in collaboration with Tashkent musicians Shorahim Shoumarov and Abdusoat Vahobov [9, p. 4]. Also, E. Romanovskaya and M. Zaripov organized an expedition to the construction of the Greater Fergana Canal, recorded a number of songs from the population, and some of the materials of the expedition were published in 1941 [9, p. 4].

Samples of folklore collected by the staff of the Art Research Institute were included in the two-volume collection "Uzbek folk songs" composed by E. Romanovskaya and I. Akbarov in 1940, in the collection of "Songs" by I. Akbarov, in the collection "Songs of Hamza" by E. Romanovskaya in 1941. [2, p. 73].

\section{Main part}

Research has been conducted not only on Uzbek music, but also on the study of Uzbek musical instruments. In 1934, VM Belyaev from Moscow conducted research on this topic and in the same year published the work "Uzbek musical instruments" in Moscow [9, p. 4]. 
On February 15, 1939, by the decision of the USSR Soviet Socialist Republic, a folklore cabinet was established under the Union of Composers. This cabinet began recording Uzbek classical music and folk songs [10, pp. 7-8].

Tanovor has a place in the Uzbek folk music heritage as a lyrical melody, dance, song and work of art. There were more than 20 specimens of Tanovor during this period. This type of art was studied by E.E. Romanovskaya, and in 1939 his pamphlet "Tanovor" was published. As a result of EE Romanovskaya's research, unique samples of Uzbek national music were presented to the general public [18, pp. 8-9].

On the eve of the war, 200 folk songs were recorded by composer AF Kozlovsky, 72 by AS Abramsky, and 157 by composer Gershovich. Based on the materials collected as a result of the expeditions, 2 collections of Uzbek songs were published [11, pp. 5-6]. At the same time, there were a number of shortcomings in the collected folklore materials. For example, the lyrics of some collected Uzbek songs were not recorded. There is also insufficient information on who, when and where the songs were recorded [11, pp. 5-6].

\section{Results and Discussions}

During the war, the evacuation to Tashkent made a worthy contribution to the development of Uzbek musicology, professors and scientists of the Leningrad Conservatory S. Ginzburg, Yu. Tyulin, H. Kushnarev and V. Struve. In 1943, the staff of the music department of the Art Research Institute began to study the theoretical works of Central Asian scholars Abu Nasr Farabi, Abu Ali ibn Sino, Qutbiddin al-Sherazi, Abdurahman Jami, Darwish Ali Changi. As a result of the involvement of historians and orientalists A. Semenov and A. Boldirev in this work, the works of medieval scholars in the field of music, such as Darvesh Ali, Husseini, Rozi, Omulet, were translated and published [17, p. 12]. In 1947, AA Semenov translated Darvish Ali's treatise on music, Al-Husseini's work "Musical canon", NN Boldirev Jami's "Musical treatise" [12, p. 10]. However, the work of the institute staff in the study of folklore in 1943-1948 was unsatisfactory [11, pp. 5-6]. During this period, there were almost no expeditions to study Uzbek songs.

In the difficult post-war years, professors and teachers of the Tashkent Institute of Theater and Art carried out research work as well as research work. In 1946, the institute had 1 professor and 8 associate professors, and insufficient conditions were created for them to engage in research work [5, pp. 1-6]. Only 13 percent of the institute's teachers conducted the research. This year, 3 people worked on their dissertations at the institute and 8 scientific articles were published. 5 of these articles were written by Associate Professor V. E.. Khorolga, 3 M. P. Belonged to Verkhatsky [5, pp. $1-6]$.

The study of folk music was somewhat sluggish during this period. Although the Phonography Cabinet of the Tashkent State Conservatory was equipped with all the necessary equipment, in the autumn of 1948 it did not take any measures to record Uzbek music. In addition, the conservatory did not train a specialist in folklore during these years [13, p. 36]. However, on the basis of materials collected before the war, the preparation of textbooks, manuals and pamphlets continued. 1945 V. Belyaev's "Essay on the development of music culture in Uzbekistan from the distant past", "Textbook on the structure of Uzbek music", I. Akbarov's "Uzbek weddings", 1946 E. Romanovskaya's "Genres of Uzbek music", $1949 \mathrm{Yu}$. Uzbek folk songs as word devices "[14, v. 9].

In the post-war years at the Tashkent State Conservatory, especially at the Department of History, Theory and Composition, research work was carried out live, and a number of teachers of the department worked on PhD and doctoral dissertations. V.A.Uspensky, E.Romanovskaya, O.Polikarpova, T.Vizgolar are among them [15, 98-100-v.].

The lack of necessary scientific literature, especially in the conservatory library, hindered the implementation of research work [15, pp. 98-100].

In 1953, the Board of the Ministry of Culture of the USSR discussed the scientific activities of the Research Institute of Art History. The board noted that in 1952, the institute's researchers submitted 4 completed works to the publishing house, but there were many shortcomings in this regard. Many topical issues were not included in the research plan of the institute [16, pp. 98-100]. There was no research on the history of Uzbek folk music among the research conducted by researchers [16, pp. 98-100].

\section{Conclusion}

Thus, in the first half of the twentieth century, research work on music was carried out, including the recording and publication of classical music and Uzbek folk songs, as well as the organization of special expeditions. A number of enthusiastic representatives of the industry have been active in the study and recording of Uzbek folk songs. As a result of their efforts, the basis was laid for the transmission of unique musical works of their time from generation to generation. Selfless scientists and local representatives evacuated to Uzbekistan as a result of the Second World War also made a worthy contribution to the development of musicology and research in the field. 


\section{References}

[1] Karomatov F. Uzbek music in the Soviet era. - Tashkent, 1967. - B.4

[2] Rajabov I. Statuses. - Tashkent, 2006. - B.41.

[3] Romanovskaya E.E. Articles and reports. Records of musical folklore. - Tashkent, 1957. - p. 17.

[4] Tashkent city State archive. 360 fund, 1 list, 300 works, 1-6 sheets.

[5] National Archive of Uzbekistan, Fund R-2731, List 1, Case 58, page 4.

[6] Oteje, Kehinde M.J, Egboh, Fasilat Bolaji, Agranpe, Tanimowo Mautin and Mafo, Akintoye Benjamin 2020. Women in moral education and rising tide in social vices in Nigeria. International Journal on Integrated Education. 3, 9 (Sep. 2020), 1-5. DOI:https://doi.org/10.31149/ijie.v3i9.581.

[7] UzMA, R-2731-fund, 1st list, 4th case, 6th sheet.

[8] UzMA, Fund R-2731, List 1, Case 4, Sheet 7.

[9] UzMA, Fund 2744, List 1, Case 80, Sheet 4.

[10] UzMA, Fund R-2731, List 1, Work 4, Pages 7-8.

[11] UzMA, Fund 2744, List 1, Case 80, Pages 5-6.

[12] UzMA, R-2731-fund, 1-n-list, 58-work, 10-sheet.

[13] UzMA, Fund 2744, List 1, Case 80, Sheet 36.

[14] UzMA, R-2731-fund, 1-n-list, 58-work, 9-sheet.

[15] UzMA, fund 837, list 32, case 7206, pages 98-100.

[16] UzMA, Fund 2087, List 1, Case 689, Pages 9-11.

[17] Bikash Sharma 2020. Plato, Aristotle \& the Dialectics of Poetry. International Journal on Integrated Education. 3, 9 (Sep. 2020), 6-10. DOI:https://doi.org/10.31149/ijie.v3i9.582.

[18] Institute of Art History of the Academy of Arts of Uzbekistan. Issues of art criticism.// Collection of scientific articles. - Tashkent, 1998. - B.12.

[19] MULUGETA CHANE WUBE(MBA) 2020. The role of institutional collaborations in combating covid-19 in dessie, south wollo and oromia special zones of eastern amhara, Ethiopia. International Journal on Integrated Education. 3, 9 (Sep. 2020), 11-27. DOI:https://doi.org/10.31149/ijie.v3i8.579.

[20] G'anieva I.A. "Tanovor" in Uzbek music (in terms of historical and theoretical problems). Abstract of the dissertation submitted for the degree of Candidate of Arts. - Tashkent, 2008. - P.8-9. 